\title{
POLA PENGOBATAN PADA PASIEN CONGESTIVE HEART FAILURE (CHF) DI INSTALASI RAWAT INAP RSUD ABDUL WAHAB SJAHRANIE KOTA SAMARINDA
}

\author{
Jenny Thalia Karundeng, Wisnu Cahyo Prabowo, Adam M. Ramadhan \\ Laboratorium Penelitian dan Pengembangan Kefarmasian "Farmaka Tropis", \\ Fakultas Farmasi, Universitas Mulawarman, Samarinda, Indonesia \\ *Email: Jenythaliakarundeng@gmail.com
}

\begin{abstract}
Congestive heart failure is a disease when the heart cannot pump blood which is sufficient for the body's needs. CHF patients in general are responsible for their treatment as ACE Inhibitors, Diuretics, Beta blockers and strengthening additional drugs for comorbidities so that certain types of treatment must be given. This research aims to see and study the pattern of care given to CHF patients. The inclusion criteria in this study were adult patients suffering from CHF and guidance at the Abdul Wahab Sjahranie Hospital inpatient installation in Samarinda. The study was observed with data collection conducted prospectively and analyzed descriptively. Data about the August-October 2018 period through medical records. The data was then analyzed by patients and patterns of CHF patients. Most pravalence at 45-59 was equal to (56.66\%), female sex was equal to (53.33\%), last education was elementary school (56.66\%) and worked as an entrepreneur for $(56.66 \%)$. The most common pattern of CHF treatment is the Nitrate, Spironolactone, Diuretic, Anti-Platelet and ARB groups of (43.33\%).
\end{abstract}

Keywords: Congestive Heart Failure, Treatment Pattern, Prospective

\begin{abstract}
ABSTRAK
Congestive Heart Failure adalah suatu keadaan dimana jantung tidak dapat memompa darah yang mencukupi untuk kebutuhan tubuh. Pasien $C H F$ pada umum nya harus diberikan sedikitnya empat jenis pengobatan yakni ACE Inhibitor,Diuretik, Beta bloker dan memerlukan obat tambahan untuk penyakit penyerta sehinggga harus diberikan beberapa jenis pengobatan. Penelitan ini bertujuan untuk melihat karakteristik dan mengetahui pola pengobatan yang digunakan . Kriteria inklusi pada penelitian ini yaitu pasien dewasa yang menderita $C H F$ dan dirawat di Instalasi Rawat Inap RSUD Adul Wahab Sjahranie Samarinda. Penelitian bersifat observasional dengan pengambilan data dilakukan secara prospektif dan dianalisis secara deskriptif. Data diambil pada periode agustus-Oktober 2018 melalui rekam medik. Data tersebut selanjutnya dianalisis karakteristik pasien dan pola pengobatan pasien $C H F$. Pravalensi terbanyak pada usia 4559 sebesar $(56.66 \%)$, jenis kelamin perempuan sebesar $(53.33 \%)$, pendidikan terakhir SD (56.66\%) dan berkerja sebagai Wiraswasta sebesar (56.66\%). Pola pengobatan $\mathrm{CHF}$ yang
\end{abstract}


paling banyak terdapat yaitu golongan Nitrat, Spironolakton, Diuretik, Anti Platelet dan ARB sebesar (43.33\%).

Kata Kunci: Congestive Heart Failure, Pola Pengobatan,Prospektif.

DOI: https://doi.org/10.25026/mpc.v8i1.328

\section{PENDAHULUAN}

Penyakit Congestive Heart

Failure (CHF) merupakan masalah yang menjadi perhatian didunia saat ini, Congestive Heart Failure (CHF) merupakan salah satu penyebab kematian tertinggi didunia. Congestive Heart Failure (CHF) adalah suatu keadaan dimana jantung tidak dapat memompa darah yang mencukupi untuk kebutuhan tubuh yang dapat disebabkan oleh gangguan kemampuan otot jantung berkontraksi atau meningkatnya beban kerja dari jantung. Gagal jantung kongestif diikuti oleh peningkatan volume darah yang abnormal dan cairan interstisial jantung. (Fajriansyah,2016)

Data dari organisasi kesehatan dunia (WHO) menyebutkan 17,3 juta orang meninggal akibat penyakit kardiovaskular pada tahun 2008 mewakili $30 \%$ dari semua kematian global. Dari kematian ini, diperkirakan 7,3 juta disebabkan oleh penyakit jantung. Pravelensi $(\mathrm{CHF})$ di Indonesia, penyakit kardiovaskular telah menjadi pembunuh nomor satu dan prevalensi penyakit jantung di Indonesia dari tahun ke tahun semakin meningkat. Provinsi dengan prevalensi penyakit jantung koroner pada umur $\geq 15$ tahun menurut diagnosis dokter ialah Provinsi Kalimantan Timur (22\%), Nusa Tenggara Timur $(4,4 \%)$. Kemudian disusul oleh Sulawesi Tengah $(3,8 \%)$ dan Sulawesi Selatan (2,9\%). Sedangkan revalensi terendah terdapat di Provinsi Riau (0,3\%), Lampung $(0,4 \%)$, Jambi $(0,5 \%)$, dan Banten $(0,2)$ (Riskesdas.2013).
Dari data tersebut memberikan informasi bahwa masalah Congestive Heart Failure perlu mendapatkan perhatian dan penangganan yang baik. Mengingat prevalensi yang tinggi dan dampak yang ditimbulkan cukup berat, maka dari itu diperlukan penelitian mengenai pola pengobatan penyakit Congestive Heart Failure agar dapat digunakan sebagai salah satu bahan acuan dalam peningkatan mutu pelayanan medis serta peningkatan efektivitas dan tingkat keberhasilan dalam mengatasi kasus $\mathrm{CHF}$.

\section{METODE PENELITIAN}

Metode penelitian ini menggunakan rancangan penelitian observasional,yaitu penelitian yang dilakukan dengan tujuan utama untuk penjabaran datadan membuat gambaran atau deskriptif tentang suatu keadaan secara objektif. Metode pengambilan sampel yang digunakan adalah metode purposive sampling. Penelitian dilakukan dengan menganalisa rekam medik pada setiap pasien $\mathrm{CHF}$ di Instalasi Rawat Inap RSUD Abdul Wahab Sjahranie Samarinda kemudian selanjutnya ditentukan karakteristik pasien dan dan menetukan pola pengobatan pada pasien CHF di RSUD Abdul Wahab Sjahranie Samarinda periodeAgustus-Oktober 2018.

Populasi penelitian ini adalah pasien yang menderita Congestive Heart Failure $(\mathrm{CHF})$ yang berada di Instalasi rawat inap RSUD Abdul Wahab Sjahranie Samarinda. Sampel penelitian adalah pasien pasien $\mathrm{CHF}$ dengan atau 
tanpa penyakit penyerta yang memenuhi kriteria inklusi. Kriteria inklusi yaitu pasien berusia lebih dari 40 taun dan memiliki rekam medik lengkap.

Pengumpulan data dilakukan dengan lembar pengumpulan data yang memuat nomor rekam medik pasien, usia, jenis kelamin, perkerjaan, tingkat pendidikan, pengobatan yang digunakan dan dosis obat.Data yang diperoleh selanjutnya di analisa secara deskriptif meliputi karakteristik dan pola pengobatan disajikan dengan cara tabulasi.

\section{HASIL DAN PEMBAHASAN}

Penelitian ini dilakukan di RSUD Abdul Wahab Sjahranie Samarinda. pasien yang dikumpulkan pada penelitian ini sebanyak 30 orang pasien yang menjadi responden. Data pasien tersebut selanjutnya dianalisis karakteristiknya berdasarkan usia,jenis kelamin,pendidikan dan perkerjaan. Gambaran distribusi pasien $C H F$ rawat inap di RSUD Abdul Wahab Sjahranie Samarinda disajikan pada grafik 1 dan 2.

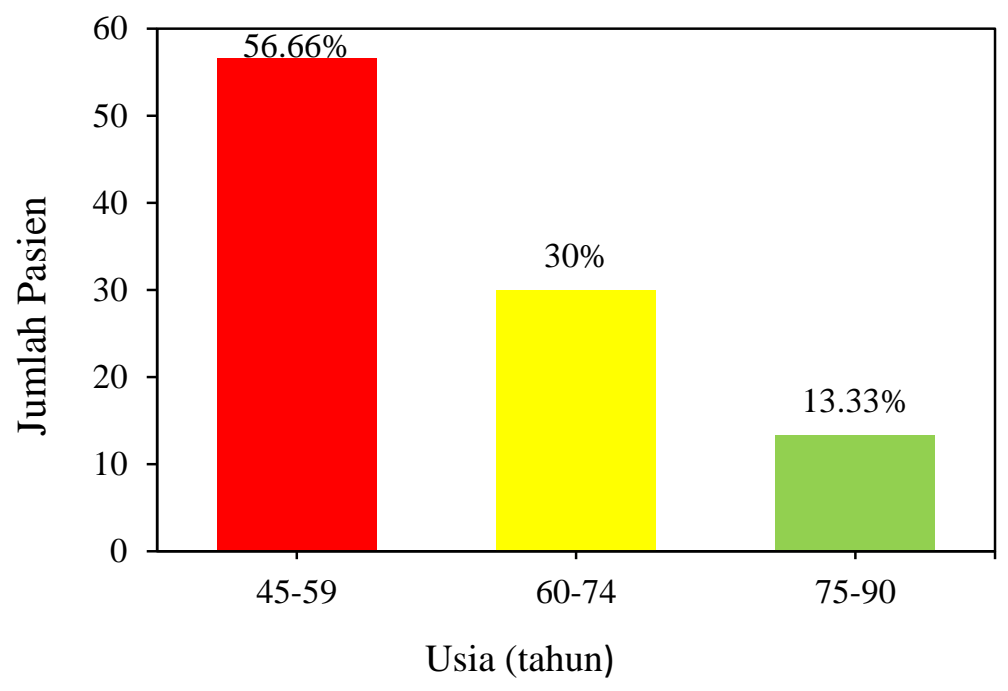

Grafik 1. Pasien CHF berdasarkan Usia

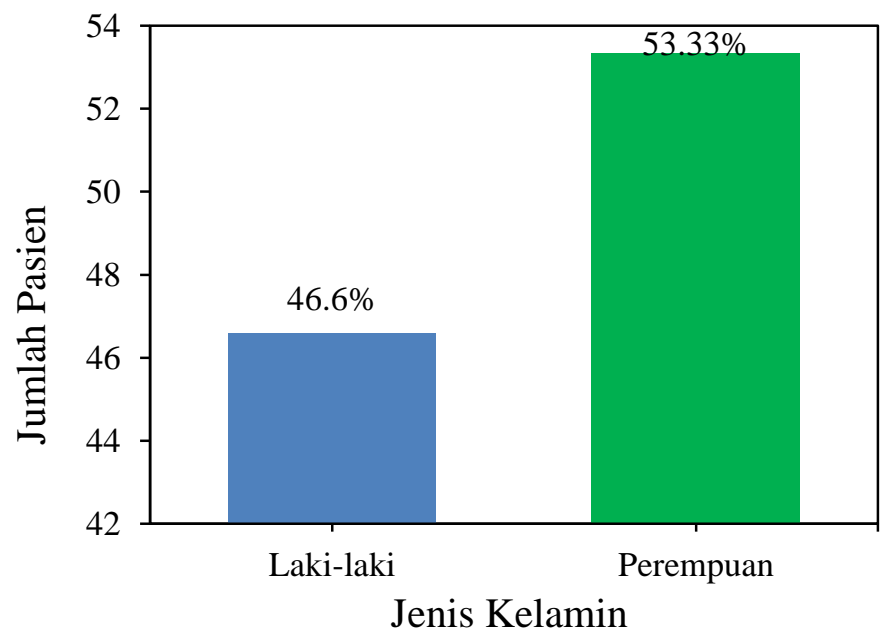

Grafik 2. Pasien CHF berdasarkan Jenis Kelamin. 
Berdasarkan pada grafik.1 diketahui bahwa usia terbanyak yang menderita $\mathrm{CHF}$ antara usia >40 tahun. Hasil penelitian ini sejalan dengan data kemenkes 2013 bahwa penderita gagal jantung paling banyak pada rentang umur 40 tahun ke atas. Secara teoritis fungsional organ-organ tubuh akan menurun seiring dengan bertambahnya usia hal tersebut merupakan salah satu faktor yang mempengaruhi terjadinya gagal jantung pada pasien lanjut usia dan selain itu gagal jantung biasanya berkembang menjadi memburuk. Gagal jantung dapat terjadi akibat penyakit kardiovaskular yang di derita lama diikuti dengan kerja organ yang menurun (Villanuve, Alfonso, 2016).

Berdasarkan Grafik 2 jenis kelamin diketahui bahwa perempuan lebih banyak menderita $\mathrm{CHF}$ dbandingkan dengan laki-laki yaitu dengan presentase $(53,33 \%)$ dimana hal tersebut sesuai dengan data Riset Kesehatan 2013 jumlah penderita $C H F$ yang paling banyak Perempuan. Secara teoritis ada perbedaan risiko antara pria dan wanita pada usia muda.pria lebih berisiko dibandingkan wanita karena secara alami wanita memproduksi hormon estrogen, sehingga berisiko rendah terkena penyakit jantung dibandingkan pria. Namun perbedaan ini akan hilang saat wanita mengalami menopause, dimana pada saat itu kolesterol LDL meningkat yang menyebabkan perempuan lebih berisiko terkena penyakit jantung (Yenni, Sabrian.2014)

Kelompok pravelensi tertinggi sebagian besar yaitu 17 orang yaitu $(56,66 \%)$ pendidikan terakhir SD (Sekolah Dasar).Dimana seseorang yang memiliki pendidikan rendah menyebabkan seseorang tersebut memiliki keterbatasan pengetahuan dan informasi sehingga kurangnya motivasi untuk menjaga kesehatan dengan tingkat pendidikan yang tingggi akan meningkatkan pengetahuan serta mudah dalam menerima informasi sehingga memiliki keinginan untuk menjaga kesehatan dan meningkatkan kualitas hidup (Agrina ed al,2011).

Sebagian besar responden yaitu 17 pasien $(56.66 \%)$ berkerja sebagai Wiraswasta. Penelitian ini sejalan dengan penelitian sebelumnya dimana angka kejadian pada pasien $C H F$ paling banyak pada seseorang yang berkerja sebagai wiraswasta (Yenni,Sabrian.2014).Secara teoritis seseorang yang melakukan kerja yang berat dan belebihan mempunyai resiko terkena penyakit hipertensi, dapat menyebabkan terjadinya hipertrofi ventrikel kiri yang terjadinya disfungsi diastolik dan meningkatkan resiko gagal jantung. (Kaplan,Schub,2010).

Dari data yang diperoleh pola pengobatan Pasien $C H F$ di RSUD Abdul Wahab Sjahranie Samarinda. terdapat pasen dengan atau tanpa penyakit penyerta seperti Diabetes Militus dan PPOK dimana obat yang diberikan juga ditujukkan untuk mengatasi penyakit penyerta.

Pola pengobatan di RSUD Abdul Wahab Sjahranie dapat dilihat pada Tabel 1 dan Tabel 2. yaitu dimana pola pengobatan pasien $C H F$ Sebanyak 30 pasien $C H F$ di RSUD Abdul Wahab Sjahranie menerima obat golongan Diuretik dan Nitrat. Dimana dapat dilihat jelas penggunaan obat yaitu ISDN, Spirnolakton dan Furosemide terdapat 6 orang (20\%), pola pengobatan selanjutnya yaitu ISDN, Spirnolakton dan penambahan obat CPG dan Candensartan dimana terdapat 13 orang $(43,33 \%)$ dan pola pengobatan ketiga yaitu digunakan obat ISDN, Spirnolakton, Furosemide dan Captopril terdapat 6 orang $(20 \%)$.

Pengunaan Furosemide pada pasien $C H F$ di Instalasi Rawat Inap di RSUD Abdul Wahab Sjahranie Samarinda yaitu digunakan untuk membuang cairan atau garam berlebih didalam tubuh melalui urine dan meredakan pembengkakan yang 
disebabkan oleh gagal jantung. Secara teoritis golongan diuretik berperan penting dalam $\mathrm{CHF}$ dengan mengurangi volume cairan melalui penghambatan reabsorbsi garam dan air dan penggunaan spironolakton atau diuretik hemat kalium dikombinasikan dengan diuretik loop membuat terjadinya diuresis natrium tanpa terjadi hyperkalemia atau hipokalemia dan dapat menurunkan gangguan pernafasan pada pasien akibat edema faringeal (Tammy,Scot,2002).

Tabel 1. Pola pengobatan pasien CHF di RSUD Abdul Wahab Sjahranie

\begin{tabular}{|c|c|c|c|c|}
\hline No. & $\begin{array}{c}\text { Golongan } \\
\text { Obat }\end{array}$ & Nama Obat & Jumlah $(n=25)$ & $\begin{array}{c}\text { Presentase } \\
(\%)\end{array}$ \\
\hline \multirow[t]{3}{*}{1.} & Nitrat & ISDN & 6 & 20 \\
\hline & Diuretik Hemat Kalium & Spironolakton & & \\
\hline & Diuretik Loop & Furosemide & & \\
\hline \multirow[t]{5}{*}{2.} & Nitrat & ISDN & 13 & 43.33 \\
\hline & Diuretik Hemat Kalium & Spironolakton & & \\
\hline & Diuretik Loop Anti Platelet & Furosemide & & \\
\hline & ARB & $\mathrm{CPG}$ & & \\
\hline & & Candesartan & & \\
\hline \multirow[t]{5}{*}{3.} & Nitrat & ISDN & 6 & 20 \\
\hline & Diuretik Hemat Kalium & Spironolakton & & \\
\hline & Diuretik Loop ACE Inhibitor & Furosemide & & \\
\hline & & Captopril & & \\
\hline & TOTAL & & & \\
\hline
\end{tabular}

Tabel 2. Pola pengobatan pasien CHF dengan penyakit penyerta RSUD Abdul Wahab Sjahranie Samarinda

\begin{tabular}{|c|c|c|c|c|c|c|}
\hline No. & $\begin{array}{c}\text { Golongan } \\
\text { Obat }\end{array}$ & & Nama Obat & $\begin{array}{c}\text { Obat Penyakit } \\
\text { Penyerta }\end{array}$ & $\begin{array}{l}\text { Jumlah } \\
(n=25)\end{array}$ & $\begin{array}{c}\text { Presentase } \\
(\%)\end{array}$ \\
\hline \multirow[t]{4}{*}{1.} & Nitrat & & ISDN & Novorapid & 3 & 10 \\
\hline & Diuretik Hemat Kalium & & Spironolakton & & & \\
\hline & Diuretik Loop & & Furosemide & & & \\
\hline & ACEI & & Captopril & & & \\
\hline \multirow[t]{4}{*}{2.} & Nitrat & & ISDN & Nebu & 2 & 6.6 \\
\hline & Diuretik Hemat & Kalium & Spironolakton & Combivent & & \\
\hline & Diuretik Loop ACEI & & $\begin{array}{l}\text { Furosemide } \\
\text { Ramimpril }\end{array}$ & & & \\
\hline & \multicolumn{4}{|c|}{ TOTAL } & & 25 \\
\hline
\end{tabular}

Penggunaan ISDN (Nitrat) pada pasien $\mathrm{CHF}$ di Instalasi Rawat Inap RSUD Abdul Wahab Sjahranie Samarinda dimana obat ini dapat mengatasi rasa nyeri pada pasien dan untuk melebarkan pembuluh darah,meningkatkan aliran darah, serta memperlancar aliran darah dan oksigen menuju otot jantung. Pengguaan captopril pada pasien $C H F$ digunakan dalam pemeliharaan tekanan darah sehingga tekanan darah tetap berada pada rentan normal. Secara teoritis golongan $A C E$ Inhibitor dapat menghambat kerja angiotensin II yang berperan dalam patofisiologi gagal jantung dan patologi 
remodeling miokaridum yang menyebabkan perburukan kondisi jantung. (Gilman et al.2008)

Penggunaan obat Candensartan pada beberapa pasien gagal jantung dimana penggunaan obat ini dapat digunakan untuk memelihara tekanan darah sehingga tidak meningkat dan memerparah kondisi pasien. Pengobatan Candensartan juga dapat diberikan pada pasien yang intoleran dengan ACE Inhibitor. Penggunaan Clopiidogril pada pasien $C H F$ juga digunakan pada beberapa pasien $C H F$ di RSUD Abdul Wahab Sjahranie Samarinda. Sesuai dengan teoritis dimana obat ini diberikan kepada pasien yang berisiko mengalami serangan jantung dan mencegah terjadinya penyakit jantung lain. Dimana obat ini berkerja dengan memblok reseptor adenosine difosfat (ADP) sehingga tidak terjadi aktivitasi platelet dan pembekuaan darah. (Amir Syarif.et al.2007)

Pasien $C H F$ dengan penyakit penyerta PPOK diperoleh presentase $(10 \%)$ obat yang diberikan sama dengan pengobatan $\mathrm{CHF}$ tunggal namun ditambahkan obat Nebu Combivent dimana obat ini merupakan kombinasi dari albuterol dan ipratropium yang bermanfaat untuk terapi penjagaan kronik dari PPOK (Williams,Judith.2014). Pasien $\mathrm{CHF}$ dengan penyakit penyerta Diabetes diperoleh presentase $(6.66 \%)$ diberikan obat tambahan Novorapid dimana dapat menekan tingkat gula darah berlebih didalam tubuh. (Utami.2003)

Terdapat beberapa faktor yang mempengaruhi pemberian obat pada pasien diantaranya pertimbangan manfaat resiko, penggunaan obat yang aling dikenal dan teruji secara klinis, penyesuaian obat dengan kebutuhan individu, penyesuaian dosis obat secara individual dan pemilihan cara pemberian obat yang aman dan memberikan hasil baik. (Junaidi.2012).

\section{KESIMPULAN}

Pravalensi terbanyak pada usia 45-59 sebesar (56.66\%), jenis kelamin perempuan sebesar $(53.33 \%)$, pendidikan terakhir SD $(56.66 \%)$ dan berkerja sebagai Wiraswasta sebesar (56.66\%). Pola pengobatan $\mathrm{CHF}$ yang paling banyak terdapat yaitu golongan Nitrat, Spironolakton, Diuretik, Anti Platelet dan ARB sebesar (43.33\%).

\section{DAFTAR PUSTAKA}

[1] Agrina, Rini, Hairitama.2011. Kepatuhan Lansia Penderita Hipertensi dalam Pemenuhan Diet Hipertensi. Jurnal keperawatan Universitas Riau. Vol. No. 1.

[2] Amir Syarif, Purwantyastuti Ascorbat, Ari Estuningtyas, Rianto Setiabudy, Arini Setiawati, Armen Muchtar.2007. Farmakologi dan Terapi. Edisi 5. Gaya Baru: Jakarta:Balitbang Kemenkes Republik Indonesia.2013.

[3] Depkes RI.2013.Riset Kesehatan Dasar. Jakarta: Badan Penelitian dan pengembangan Kesehatan Kementrian Kesehatan RI.

[4] .Fajriansyah Tahir, Kombong.2016. Kajian Drug Relation Problem (DRPs) pasien gagal jantung kongestif di RSUD Hasanudin. Journal Farmasi. No.1. Vol.5.

[5] Gilman, Hardman Joel dan Lee Limbird.2008. Farmakologi dan Terapi.Terjemahan oleh Tim Ahli bahasa Sekolah Farmasi ITB. Jakarta: Penerbit Buku Kedokteran EGC.

[6] Junaidi Iskandar.2012. Pedoman untuk Praktis Obat Indonesia (O.I). Jakarta : Bihuna Ilmu Populer.

[7] Kaplan, Schub.2010. Heart Failure In Women.Cinahl Information System. .Jurnal medical. No. 1 Vol.4:57-63.

[8] Tammy, Scoot.2002. Manual Washington Terapi Rawat Jalan Pasien. Penerbit Buku Kedokteran EGC. 
[9] Utami.2003. Tanaman Obat Yang Dapat Mengatasi Diabetes Mellitus. Agromedia Pustaka. Jakarta.

[10] Villanuve, Alfonso.2011. Heart Failure in the elderly. Jurnal of Geratric Cardiolodigy. Vol.13.

[11]William, Wilkins.2011. Nursing: Memahami Berbagai Macam Penyakit. Ahli Bahasa Paramita Indeks:Jakarta
[12]WHO. 2013. About Cardiovascular diseases. World Health Organization. Geneva

[13] Yenni, Sabrian.2014. Pengaruh Pendidikan Kesehatan dan Latihan Rehabilitas Jantung Congestive Heart Failure. Jurnal Keperawatan. Program Studi Ilmu Keperawatan Univertas Riau.Vol.1.No.3. 